\title{
田
}

\section{ESTÁGIO PROFISSIONAL E PRECARIZAÇÃO DO TRABALHO}

\author{
PROFESSIONAL INTERNSHIP AND UNSTABLE WORK
}

\author{
Jaime Hillesheim ${ }^{1}$
}

\section{RESUMO}

O artigo aborda a questão do estágio profissional no contexto da precarização do trabalho. Tem como objeto o conteúdo de proposições legislativas em tramitação na Câmara Federal que visam alterar a Lei n. 11.788/2008 - "lei do estágio". A análise indica que tais proposições só aparentemente configuram ampliação de direitos dos estudantes, mas, na essência, constituem formas de precarização do trabalho e, ao mesmo tempo, reforçam as perspectivas mercadológicas em detrimento da dimensão pedagógica do estágio.

Palavras-Chave: Estágio. Mercado de Trabalho. Precarização do Trabalho

\section{ABSTRACT}

The article discusses the issue of professional internship the context of unstable work. Its object is the content of the law proposals being processed at the Federal Legislative which seek to change the Law 11.788/2008 "Intership law". The analysis indicates that such prepositions only apparently configure extension of students' rights, but, in essence, constitute forms of precarious work and, at the same time, reinforce the market perspectives over the training pedagogical dimension.

Keywords: Internship. Work Market. Unstable Work.

$$
\text { Submissão - 10/09/2016 }
$$

$$
\text { Aceite }-13 / 01 / 2017
$$

\footnotetext{
1 Professor do Departamento de Serviço Social da Universidade Federal de Santa Catarina (UFSC). Doutor em Serviço Social pelo Programa de Pós-Graduação em Serviço Social (PPGSS) da mesma instituição e membro do Núcleo de Estudos e Pesquisa: Trabalho, Questão Social e América Latina.
} 


\section{temporolis}

\section{Introdução}

Pretendemos abordar o estágio profissional a partir de um conjunto de determinações sociais, culturais, políticas e econômicas que conforma concepções, estratégias e propostas formuladas num contexto de regressão de direitos dos trabalhadores, de mercantilização da educação e de avanço, no Brasil, "[...] do pensamento econômico que retoma o antigo desenvolvimentismo com o prefixo 'novo' (neo) sem algumas mediações históricas necessárias. A velha tragédia ganha, desta maneira, contornos de uma farsa contemporânea." (CASTELO, 2012, p. 622-623). As propostas que constituem essa farsa foram defendidas por intelectuais vinculados a um tipo de pensamento de esquerda e que vislumbravam nelas uma possibilidade de ultrapassagem "segura" do neoliberalismo. Contudo, na essência, tais proposições configuram variações da programática neoliberal que são assimiladas no interior da universidade brasileira e reproduzidas no processo de formação. Isso, por certo, repercute diretamente sobre a direção e as perspectivas do estágio profissional.

No âmbito do Serviço Social, apesar dos inúmeros esforços teóricos e políticos e da aprovação de um conjunto de normativas legais, problemas e polêmicas em relação ao estágio têm sido recorrentemente debatidos nos espaços acadêmico-profissionais. Essa recorrência revela, entre outras coisas, que muitos desafios ainda que identificados - não foram devidamente superados.

Nosso propósito, aqui, é contribuir com o debate sobre o estágio de modo geral e, em particular, no âmbito do serviço social, trazer a categoria à reflexão sobre a relação entre o estágio e a precarização do trabalho. Para isso, na primeira parte do presente artigo situamos a temática do estágio no processo de construção do projeto ético-político da categoria, enfatizando o contexto contemporâneo da sociedade brasileira e as respostas - mediadas pelo mercado de trabalho - que a profissão tem conseguido formular diante das questões suscitadas em relação ao estágio.

Em seguida, apresentamos algumas reflexões sobre a denominada "lei do estágio" (Lei n 11.788/2008), defendendo a ideia de que tal normativa corrobora com o processo de precarização do trabalho, apesar de seu conteúdo aparentemente progressista.

Num terceiro momento, problematizamos os fundamentos 


\section{tempordis}

e as perspectivas das proposições legislativas apresentadas e em tramitação na Câmara Federal, cujo objeto é o estágio profissional.

Por fim, concluímos que os estágios profissionais, em todas as modalidades e níveis de ensino, têm se constituído em formas disfarçadas ou explícitas de precarização do trabalho, muitas vezes reafirmadas pela dinâmica instaurada nos espaços de formação. A partir dessa afirmativa, socializamos alguns questionamentos sobre o estágio supervisionado em Serviço social.

\section{Situando o debate sobre o estágio em Serviço Social}

Não é nosso objetivo, aqui, aprofundar a questão do estágio no âmbito específico do Serviço Social, mas, sim, evidenciar os processos de precarização do trabalho pela mediação desse componente curricular. Ainda sim, consideramos importante trazer alguns aspectos desse debate no interior da profissão evidenciando os avanços conquistados e problemas que ainda persistem.

O Serviço Social brasileiro, na defesa de seu projeto éticopolítico - construído na luta histórica da categoria - se contrapõe à estruturação e dinâmica da sociabilidade regida pelo capital. A profissão vem sendo desafiada de maneira implacável a formular respostas às demandas apresentadas pelo mercado de trabalho e que, muitas vezes, tornam opaca a complexa realidade que as engendram. Realidade esta marcada pelo domínio do capital financeiro, pela regressão de direitos dos trabalhadores e por sucessivas derrotas políticas. A lógica mercantil que dá sustentação à política de educação no País e que, por sua vez, está em consonância com as diretrizes do Banco Mundial (BM) para atender aos interesses do capital, impõe à profissão vigilância permanente para não recuar em seu projeto éticopolítico e aderir ao pensamento (neo)conservador que tem avançado sobremaneira nas universidades.

É neste contexto que a estrutura e dinâmica do estágio profissional ganha relevância, sendo, por certo, determinadas pelos interesses e necessidades do mercado de trabalho que, conforme apontam vários estudos, é cada vez mais precarizado. Essa tendência à precarização e à flexibilização, especialmente quando se trata da inserção laboral dos jovens, acaba por reiterar processos que condenam esse segmento dos trabalhadores ao trabalho pela simples 


\section{temporolis}

sobrevivência. (POCHMANN, 2007).

No caso específico do Serviço Social, no acervo técnicoacadêmico produzido ao longo das últimas décadas, verifica-se que a questão é reiteradamente colocada em discussão nos eventos científicos. E, conforme já assinalava lamamoto (1995, p. 193) no início dos anos de 1990, "[...] a questão do ensino da prática em Serviço Social representa um aspecto dos mais polêmicos do debate contemporâneo sobre a formação profissional." Contudo, a autora também advertia que já naquele período, pouco se tinha "[...] avançado no amadurecimento de propostas que [...] [representassem] um salto substantivo no processo de qualificação teórico-político de profissionais." (IAMAMOTO, 1995, p. 193).

O fato é que o estágio supervisionado em Serviço Social continua presente hoje no debate acadêmico e na pauta dos órgãos representativos da categoria e, apesar de se ter construído importantes respostas práticas, teóricas, políticas e legais, estas parecem ser ainda insuficientes para o enfrentamento dos novos (e velhos) problemas relacionados à questão, especialmente quando esta não é relacionada às determinações mais gerais que conformam a realidade social contemporânea.

Nas atuais diretrizes curriculares para os cursos de Serviço Social o estágio supervisionado é referenciado a partir de vários princípios que subsidiam a formação, dentre os quais o da indissociabilidade entre estágio e supervisão acadêmica e profissional. Ademais, as mencionadas diretrizes indicam a observância das disposições contidas na lei de regulamentação da profissão e no Código de Ética profissional do assistente social. Neste diapasão, o estágio é entendido como uma atividade de caráter pedagógico que deve permitir o desenvolvimento das competências teórico-metodológicas, éticopolíticas e técnico-operativas dos futuros assistentes sociais.

Dada a importância do estágio para a formação profissional, a Associação Brasileira de Ensino e Pesquisa em Serviço Social (ABEPSS) se empenhou na formulação da Política Nacional de Estágio. Nela, a entidade problematiza, dentre outros aspectos, o estágio no contexto da universidade brasileira, de modo a apontar as tensões e desafios existentes.

É neste documento, também, que restam evidenciadas as 


\section{tempordis}

responsabilidades dos sujeitos envolvidos na atividade pedagógica do estágio supervisionado em Serviço Social, dando destaque para aqueles centrais: os supervisores (acadêmico e de campo) e o estudante estagiário.

A Política Nacional de Estágio - formulada no debate nacional promovido pela ABEPSS - serve como instrumento técnico-político para nortear a condução das políticas institucionais de estágio implementadas no interior das universidades. Contudo, não tem natureza imperativa e sua efetividade está condicionada a um conjunto de elementos sobre o qual nem sempre os profissionais e estudantes - especialmente os mais diretamente envolvidos nas atividades de estágio - têm controle e, por isso, não conseguem imprimir na condução desse componente curricular aquela perspectiva defendida pelo coletivo da categoria.

Outro importante instrumento para garantir a qualidade e a natureza pedagógica do estágio supervisionado em Serviço Social é a Resolução $n^{\circ}$ 533/2008 do Conselho Federal de Serviço Social (CFESS), editada no mesmo período de promulgação da Lei $n^{\circ} 11.788 / 2008$. Aquela normativa não regulamenta, em particular, a atividade do estágio supervisionado em Serviço Social, mas, sim, a supervisão do estágio profissional na área, entendida como uma atividade privativa do assistente social.

Esse conjunto de normativas, contudo, nem sempre é usado na defesa das prerrogativas profissionais, tanto por parte de estudantes estagiários quanto por parte de supervisores em face das precárias condições de trabalho. Isso evidencia que as normas legais são insuficientes para dar efetividade aos preceitos nelas contidos. Sem desprezo a estes mecanismos formais construídos pelo conjunto da categoria ao longo da sua história, a competência teórico-metodológica para fazer a crítica necessária à realidade social e a ação política dos profissionais, por meio de suas organizações representativas, continua, como sempre foi, essencial para fazer avançar e dar efetividade ao projeto ético-político.

A despeito do conhecimento produzido sobre o tema pelo Serviço Social e por outras áreas afins, tem-se enfrentado, cotidianamente, inúmeros problemas em relação ao estágio supervisionado. Tais problemas têm sua gênese numa lógica que faz sucumbir o caráter pedagógico dessa atividade em face dos interesses 


\section{temporollis}

do mercado de trabalho capitalista. A substituição de profissionais por estagiários, as relações clientelistas entre instituições de ensino e campos de estágio para que sejam garantidos os espaços para a sua realização, as condições precárias de trabalho dos supervisores (acadêmico e de campo), a concepção de estágio como mera prestação de serviços, a dominância do caráter técnico em detrimento da necessária articulação desse caráter com as dimensões teóricometodológica e ético-política nas práticas de estágio, o estágio como estratégia de sobrevivência de estudantes e como possibilidade de permanência na academia, entre outros tantos problemas, revelam como o tema atravessa a realidade da formação profissional em Serviço Social (mas não só) e precisa permanecer na pauta de lutas da categoria. Ademais, na medida em que o estágio tem sua precípua função descaracterizada, serve, ao lado de um conjunto extenso de outras atividades cotidianas dos estudantes trabalhadores, como óbice para uma "vida cheia de sentido". E, nessa direção, constituise em mais um mecanismo viabilizador do estranhamento (LUKÁCS, 1979), haja vista que tal atividade, nas condições em que se objetiva, não contribui para a realização do gênero humano. Assim, se se pensar a educação como mediação de processos revolucionários, é preciso ter em mente que as ações educativas - entre elas o estágio - devem fomentar "[...] a autotransformação consciente dos indivíduos [...]." Esses processos exigirão, ainda, "[...] a universalização da educação omnilateral e a recuperação do sentido ontológico do trabalho na formação do ser social." (LEHR, 2011, p. 167).

Feitas essas considerações é importante dizer que, àquela gama de problemas, soma-se o fato de que tramita no legislativo federal um conjunto de iniciativas legais que trata do estágio em geral e que, por certo, pode trazer importantes rebatimentos no estágio em Serviço Social. Aparentemente progressistas, os projetos de lei que estão em tramitação reforçam, ainda mais, a lógica mercantil que tem dominado o debate sobre a questão.

\section{Comentários sobre a chamada "lei do estágio"}

Nossas ponderações, aqui, terão como base a Lei $n^{\circ} 11.788 / 2008$ que dispõe sobre o estágio de estudantes e subsidia primordialmente a política de estágio no âmbito nacional, tanto nas universidades como em outras instituições de ensino médio, técnico, especial 


\section{tempordis}

e fundamental (do $5^{\circ}$ ao $9^{\circ}$ ano). A reformulação das normativas relativas ao estágio constituía uma das ações previstas no Plano de Desenvolvimento da Educação, aprovado em 2007, pelo governo federal.

Apesar de a referida lei definir o estágio como um "ato educativo escolar supervisionado" e que, por isso, deve fazer "parte do projeto pedagógico do curso" de maneira a permitir o "[...] aprendizado de competências próprias da atividade profissional", contraditoriamente, a mesma normativa indica que o estágio deve preparar o estudante "para o trabalho produtivo." (BRASIL, 2008). Neste sentido, a lei mesma objetiva explicitamente o ingresso do estudante no mercado de trabalho.

Não por acaso a lei em comento define regras que muito aproximam o estágio das relações de emprego, ainda que se afirme a sua natureza distintiva. Na prática o que se observa é que esta distinção não é tão essencial e a norma tem contribuído, sim, para a precarização do trabalho. Alguns dos direitos constantes nos dispositivos da chamada "lei do estágio" são típicos dos que se inserem em relações de emprego. Em sendo assim, tem-se concretamente a constituição de um contingente de trabalhadores que passam a se identificar como empregados especiais, caso preencham os requisitos impostos pela norma: matrícula e frequência regular numa instituição de ensino; termo de compromisso entre o estagiário, a instituição de ensino e a parte concedente do estágio; compatibilidade entre as atividades desenvolvidas no estágio e aquelas definidas nos instrumentos formais pactuados.

Neste sentido, a "lei do estágio" garantiu direitos que, em face das condições de vida da grande maioria dos estudantes brasileiros, parecem ser justo motivo de comemoração e de prestígio. Contudo, esta aparência progressista, no nosso entendimento, esconde um conjunto de estratégias que visa dispor, para o mercado de trabalho, mão de obra barata em detrimento da função pedagógica do estágio. Desta feita, a regulamentação de estágio constitui uma exceção instituída à relação empregatícia. ${ }^{2}$ Dito de outro modo, ela permite

2 O estágio profissional pode ser concebido como uma relação de trabalho, mas não de emprego, segundo a doutrina trabalhista. Neste sentido, ao diferenciar as duas relações, Maurício Godinho Delgado assevera que: "[a] primeira expressão tem caráter genérico: refere-se a todas as relações jurídicas caracterizadas por terem sua prestação essencial centrada em uma obrigação de fazer consubstanciada em labor humano. [...] A 


\section{temporollis}

que a mercadoria força de trabalho seja contratada de maneira mitigada, a despeito da legislação laboral vigente no País, forjada na luta entre capital e trabalho.

As "novidades" advindas da Lei n. 11.788/2008, portanto, fazem assemelhar ainda mais o estágio às relações de emprego, contribuindo para a ampliação dos processos de precarização do trabalho. A aprovação dessa normativa fez (re)surgir outras proposições legislativas que vão na mesmíssima direção: atender aos interesses do mercado de trabalho capitalista.

Do ponto de vista formal a desconsideração do caráter pedagógico do estágio é combatida no meio jurídico. Ainda que numa interpretação legalista e de defesa da "lei do estágio", Palmeira Sobrinho (2008, p. 8) assevera que:

A finalidade do estágio não é combater o desemprego, distribuir renda, tampouco suprir a carência imediata de mão de obra das empresas. A sua destinação é especificamente de formação educativa, afigurando-se ilegal a exploração do trabalho do estagiário com o objetivo de reduzir os custos de reprodução da força de trabalho.

Apesar das tentativas de nublar as reais intenções da "lei do estágio", os próprios órgãos estatais defendem que "[...] as disposições [...] [legais] representam uma evolução na política pública de emprego para jovens no Brasil [...]." (MTE, 2010, p. 1, grifo nosso). Os "aspectos inovadores" impressos no texto legal em comento, portanto, evidenciam seu uso também para o enfrentamento do desemprego entre os jovens trabalhadores.

A burla à legislação trabalhista é cotidianamente reiterada sob o auspício dos contratos de estágio. Na realidade do ensino superior, não só na área do serviço social, mas em todos os cursos, a violação de direitos se materializa de várias formas: na falta do supervisor acadêmico ou na falta de condições para que esta seja realizada; no número excessivo de estudantes sob a responsabilidade de um mesmo docente; na transformação da supervisão de campo num sobretrabalho do profissional que a assume repercutindo sobre a

relação de emprego, do ponto de vista técnico-jurídico, é apenas uma das modalidades especificas de relação de trabalho juridicamente configuradas. Corresponde a um tipo legal próprio e específico, inconfundível com as demais modalidades de relação de trabalho ora vigorantes." (DELGADO, 2007, p. 285). 


\section{tempordis}

qualidade do estágio; na ausência dos convênios e termos de estágio com a anuência de órgãos de fiscalização; na falta de nexo entre as atividades de estágio e a área de formação; na não realização de avaliações periódicas, etc..

No âmbito do ensino superior, mas não exclusivamente, a conivência das instituições educacionais com inúmeras irregularidades caracteriza um pacto incondicional com os interesses do mercado de trabalho na medida em que oferecem mão de obra qualificada ou em processo de qualificação em condições ótimas para o capital. Do ponto de vista ético tais instituições faltam com o compromisso assumido com seus próprios estudantes, na medida em que a reiteração dessas práticas compromete a inserção futura desses no mercado de trabalho profissional após a conclusão do processo formativo em nível de graduação.

Apesar de se propagar o potencial benéfico da Lei $n$. 11.788/2008 para os estudantes, de fato, ela beneficia o mercado de trabalho capitalista, haja vista sua incontestável contribuição para dar maior flexibilidade ao uso da força de trabalho. Além disso, como já apontamos alhures, novas proposições estão em discussão no legislativo federal para fazer o capital avançar mais sobre os direitos dos trabalhadores e desvirtuar o caráter pedagógico do estágio.

\section{Estágio e precarização do trabalho}

Dirão os membros do legislativo que na atividade legiferante é impossível contemplar todas as situações que se materializam no cotidiano da vida em sociedade, especialmente em face da sua dinamicidade. Eis, pois, a razão das proposições de ajustes constantes nas leis. Isso também é sustentado quando das justificativas de alteração da Lei n. 11.788/2008. E, tão logo houve a sua promulgação, novas e velhas proposições foram (re)apresentadas no legislativo federal com vistas a realizar os "ajustes" necessários.

É importante salientar que os legisladores ao apresentarem alterações à norma em comento, em suas exposições de motivos, destacam a preocupação em não onerar a iniciativa privada e os órgãos públicos de maneira que a contratação de estagiários seja estimulada. Neste sentido, reiteradamente são reafirmadas as vantagens econômicas dessa contratação, haja vista que as partes 


\section{temporalis}

concedentes dispõem de uma mão de obra cuja capacidade se assemelha aos trabalhadores que, em geral, são celetistas - no âmbito da iniciativa privada - ou concursados - no âmbito do setor público -, com um custo muito menor. Assim, a preponderância dos interesses do mercado se mantém, ao passo que a dimensão pedagógica do estágio se torna mero acessório.

Num levantamento feito a partir da base de dados disponível no site da Câmara dos Deputados Federais constatamos um significativo número de projetos de lei que, no início do ano de 2016, estavam em tramitação naquela casa legislativa, tendo como objeto alguma dimensão da atividade de estágio.

Com o intuito de identificar as matérias a que se referem tais projetos de lei realizamos uma análise do conteúdo legislativo e das justificativas das proposições apresentadas, concentrando nossa atenção naquelas que avaliamos mais relevantes do ponto de vista das reflexões que nos propomos fazer. ${ }^{3} \mathrm{~A}$ partir dessa análise definimos alguns eixos aglutinadores das matérias em discussão relacionadas especificamente à questão do estágio, sendo eles: ampliação do universo de estudantes "beneficiários" da Lei n. 11.788/2008 - o que chamamos de perspectiva de ampliação do exército de estagiários; a prorrogação do tempo de estágio; as formas de acesso às vagas de estágio; a natureza do estágio; e a progressiva e precária aproximação do trabalhador estagiário à figura jurídica do trabalhador empregado.

Emvirtude de limites objetivos que nosimpedem deabordarmos todas essas questões, no presente artigo, problematizaremos apenas esse último aspecto mencionado.

\section{Da progressiva e precária aproximação do trabalhador estagiário à figura jurídica do trabalhador empregado}

Grande parte das proposições legislativas que visam alterar

3 Nesse estudo analisamos os seguintes projetos de lei que estavam em tramitação na Câmara Federal dos Deputados, no início de 2016: 1396/2015; 1368/2015; 1141/2015; 1134/2015; 978/2015; 963/2015; 716/2015; 7486/2014; 5104/2013, 5462/2013, 5695/2013, 3158/2012, 4443/2012, 4598/2012, 4697/2012, 4813/2012, 268/2011, 563/2011, 2673/2011, 2685/2011; 2942/2011, 7109/2010, 7653/2010, 7867/2010, 4579/2009, 5165/2009. Essas proposições foram apresentadas por deputados de vários partidos: PDT, PSD, PR, PP, PRB, PV, PT, PSC, PSB, DEM, PMDB, PTB, PSDB, etc. 


\section{tempordis}

a Lei n. 11.788/2008 tende a buscar uma equiparação dos direitos do estagiário aos direitos assegurados ao trabalhador com vínculo de emprego, sem, contudo, pôr em questão os benefícios que os contratos de estágio garantem às partes concedentes. A similitude de direitos (e obrigações) e vantagens a que nos referimos, por óbvio, é mais nitidamente percebida na modalidade não obrigatória do estágio, conforme se denota da legislação em comento.

De acordo com a doutrina trabalhista os requisitos caracterizadores da relação de emprego são: trabalho por pessoa física, pessoalidade, onerosidade, não eventualidade, subordinação e alteridade.

Da mesma forma que um empregado, o estagiário para ser contratado como tal deve ser uma pessoa física, na condição de estudante. Do mesmo modo, assim como um empregado, deve o estagiário exercer pessoalmente suas atividades, não podendo delegá-las a outrem. A não eventualidade presente na relação de emprego, por certo caracteriza também as práticas de estágio e, dadas as exigências que se fazem ao estagiário, este acaba por integrar-se aos fins das organizações nas quais se vincula. Não se trata, pois, de uma atividade esporádica ou episódica, mas que implica certa permanência do vínculo entre o estagiário e a instituição/órgão/ empresa que o "admite". Há que se destacar ainda que, conforme a lei do estágio dispõe, a duração dessa atividade curricular, na mesma parte concedente, não poderá exceder 2 (dois) anos, salvo quando se tratar de estagiário com deficiência (BRASIL, 2008). A subordinação que advém da relação jurídica entre empregado e empregador por meio de um contrato de trabalho também é verificada entre o estagiário e quem o contrata, haja vista a exigência dos convênios e termos de estágio nos quais são explicitadas as obrigações e direitos das partes envolvidas. Essa subordinação se verifica, ainda, no fato de o estagiário estar sujeito às determinações, ao comando e ao controle da parte concedente. É muito comum, por exemplo, que a "jornada de trabalho" do estagiário seja controlada pelos mais variados mecanismos. Por fim, o estagiário não pode assumir os riscos da atividade desenvolvida por quem o contrata, tal como um empregado, demonstrando que alteridade também se verifica nos contratos de estágio, ainda que essa não seja um requisito essencial da relação de emprego, segundo alguns juristas do direito do trabalho. Além de todo o exposto, verificamos que o estágio, particularmente 0 curricular não obrigatório, tem sido remunerado, principalmente com 


\section{temporollis}

o advento da Lei n. 11.788/2008. Desta feita, a onerosidade presente na relação de emprego é similarmente observada em parte significativa dos contratos de estágio.

Ao analisar as similaridades entre o trabalhador estagiário e o empregado celetista, Maurício Godinho Delgado (2008, p. 324) se posiciona no seguinte sentido:

Repita-se que o estagiário traduz-se em um dos tipos de trabalhadores que mais se aproximam da figura jurídica do empregado - sem que a legislação autorize, porém, sua tipificação como tal. De fato, no estágio remunerado, esse trabalhador intelectual reúne, no contexto concreto de sua relação com o concedente do estágio, todos os elementos fático-jurídicos da relação empregatícia (trabalho por pessoa física, com pessoalidade, não-eventualidade, onerosidade e sob subordinação ao tomador dos serviços). Não obstante, a ordem jurídica, avaliando e sopesando a causa e objetivos pedagógicos e educacionais inerentes à relação de estágio - do ponto de vista do prestador de serviços, nega caráter empregatício ao vínculo formado.

Para estimular a contratação de estagiários às partes concedentes, é oferecido legalmente um conjunto de benefícios: não são devidos encargos sociais, trabalhistas e previdenciários. Portanto, os contratantes dispõem de uma força de trabalho específica, com um custo muito menor.

Ainda que seja necessário pesquisar mais a relação entre o oferecimento de vagas de estágio obrigatório e as de não obrigatório, aqueles incentivos também ajudam a explicar a falta de vagas para a primeira modalidade em algumas unidades de ensino, na medida em que aquelas instituições concedentes que possuem um número significativo de estagiários realizando o de caráter não obrigatório, declinam da seleção de estudantes que pretendem realizar o de caráter obrigatório, porque teriam que dispor de um profissional para assumir as responsabilidades exigidas pelas instituições de ensino ${ }^{4}$. Essa postura de preferência por aquela modalidade de estágio pode indicar, no mínimo, que as regras instituídas legalmente sobre as condições de realização dos estágios são facilmente burladas,

4 Ademais, a legislação impõe limites ao número de estagiários - independentemente de estarem realizando estágio obrigatório ou não - em relação a cada profissional supervisor. 
em particular, quando se trata daqueles contratos de estágio não obrigatório. Isso porque a maioria das unidades acadêmicas não tem estrutura para fazer o devido acompanhamento pedagógico nem mesmo do estágio curricular obrigatório, quiçá da outra modalidade. Não por acaso em algumas universidades já se cogita a realização da "supervisão de estágio online", estratégia que responderia às inúmeras denúncias de descumprimento das normas legais, em especial quanto à supervisão acadêmica das atividades desenvolvidas pelos estudantes nas instituições concedentes.

Admitindo que estagiários desempenham funções com qualidade e capacidade semelhantes a de profissionais, alguns legisladores, defendendo interesses de determinados segmentos sociais, inclusive os de estudantes, propõem alterações na "lei do estágio" no sentido de ampliar os benefícios nela previstos.

As proposições mais recorrentes têm como objeto a questão da remuneração, traduzida sob a denominação de bolsa de estágio. Neste particular as sugestões são muito variáveis. Alguns defendem que o valor da bolsa não pode ser inferior ao valor do salário mínimo vigente no País. Outros propõem que o pagamento seja diferenciado em conformidade com o nível de ensino, mas compulsório. Assim, os estudantes enquadrados nas condições previstas no inciso I, do art. 10 da Lei n. 11.788/2008 teriam direito ao pagamento de (1) um salário mínimo, os enquadrados no inciso II do mesmo dispositivo seriam remunerados em (1) um salário mínimo e meio e, os estudantes de nível superior, nas condições previstas no inciso III, teriam garantido o pagamento de bolsa no valor de 2 (dois) salários mínimos. O argumento é de que a valorização da remuneração dos estagiários coibiria as práticas de exploração dessa força de trabalho, haja vista que a atividade de estágio é reconhecidamente sub-recompensada.

Há ainda algumas proposições voltadas para garantir que os estágios remunerados, em particular para os estudantes em níveis de ensino precedentes ao superior, sejam oferecidos exclusivamente para jovens entre 14 e 17 anos, sem vínculo de empregos, com renda familiar que os caracterize como pobres e até que eles completem 18 anos. Estes jovens teriam direito a uma bolsa de 1 (um) salário mínimo, além do auxílio transporte e alimentação.

Já as propostas de remuneração em relação aos estágios curriculares obrigatórios aparecem em menor número, mas existem. 


\section{temporalis}

Em geral, estas proposições defendem que a União deve garantir, através da criação de um programa específico, no ensino superior, bolsas para os estudantes cujos cursos não tenham vagas suficientes para a realização desse tipo de estágio. Contudo, o acesso a este benefício estaria limitado aos estudantes de famílias cuja renda per capita fosse idêntica à definida pela legislação para o acesso aos programas de bolsas de estudos em instituições privadas de ensino superior.

Em sendo aprovada, esta proposta caracterizaria uma duplicidade de ação, haja vista a existência de uma política de permanência sendo conduzida pelo Ministério da Educação, ainda que esta seja insuficiente para atender a demanda existente. Em relação a esta questão, o que se observa é que, mesmo no interior do movimento estudantil, essa tensão entre necessidade de subsistência e o caráter pedagógico do estágio, muitas vezes não é problematizada suficientemente. Em não sendo, relativiza-se a importância da defesa de uma política de permanência nas universidades, fato que fragiliza a capacidade de mobilização do próprio movimento estudantil em torno dessa política. $E$, mais, na medida em que a política de permanência nas universidades brasileiras não é articulada a outras importantes questões que envolvem a realidade concreta da vida do estudante trabalhador, ela acaba por constituir-se numa política que dissimula, mas não enfrenta e supera questões estruturais que obstam a permanência qualificada dos estudantes no ensino superior. Na medida em que os estudantes trabalhadores, em virtude de terem acessado à universidade, se inserem em atividades de estágio para garantirem a sua subsistência, o "tempo livre" - que deveria ser ocupado com atividades pedagógicas que contribuam para o desenvolvimento de suas capacidades humanas - é usado para aprisioná-los em trabalhos estranhados que capturam suas subjetividades e as moldam na perspectiva requerida pelo mercado de trabalho capitalista. $O$ "tempo livre" desses contingentes de estudantes trabalhadores só poderia ser usado num sentido oposto (para potencializar o desenvolvimento das capacidades do ser genérico do homem) se a eles fossem garantidas as condições básicas para a sua reprodução por outras formas que não pela venda da sua própria força de trabalho (ou disponibilidade dela para acessar a algum tipo de recurso público - bolsa - que o valha como contraprestação).

Ademais, a aprovação de um programa específico daquela natureza permitiria que a iniciativa privada - como parte concedente 
nos convênios estabelecidos com as universidades -, também tivesse à disposição um exército de estagiários sendo recompensados economicamente pelo Estado, desonerando o capital, também por esta via. Nota-se, portanto, que os representantes do capital, também por meio do estágio, vislumbram a possibilidade de se apropriar do excedente econômico produzido pelo trabalhador, disputando, de maneira enviesada, recursos públicos. Constituiria, assim, um tipo de subsídio que integraria indiretamente os mecanismos de reprodução geral do capital.

No estudo legislativo realizado identificamos, ainda, proposições que sugerem que a questão da concessão de bolsa, no caso de estágio curricular obrigatório, seja uma liberalidade da parte concedente, sendo compulsória somente em relação aos estágios curriculares não obrigatórios.

No conjunto dos projetos de lei analisado encontramos também a defesa de outras proposições que aproximam o trabalhador estagiário à figura do trabalhador empregado: pagamento de gratificação natalina ao estagiário remunerado, verba que se assemelha ao instituto celetista do $13^{\circ}$ salário; recesso remunerado que, a despeito de se destacar a sua distinção em relação ao direito trabalhista de férias, tanto no que tange à sua natureza quanto à forma de concessão, não há como negar similaridades, pois o recesso remunerado do estagiário figura como uma forma substitutiva e precária daquele direito do empregado celetista5; garantia de intervalo que antecede à extensão da jornada diária máxima de 6 (seis) horas

5 A norma legal vigente prevê que o estagiário que recebe bolsa ou outra contraprestação pelos seus serviços tem direito a um recesso remunerado, de 30 (trinta) dias, quando o estágio tenha duração igual ou superior a um ano. Prevê, ainda, que se o estágio for desenvolvido em tempo inferior, esse recesso deve ser concedido de maneira proporcional.Muitas partes concedentes, nos casos em que o estágio tem duração de 02 (dois) anos, acabam por conceder os primeiros 30 (trinta) dias e, em virtude do fim do contrato de estágio, não concedem o segundo período de recesso remunerado. Neste sentido, há a defesa, nas proposições legislativas analisadas, de que seja imposta à parte concedente a concessão do recesso remunerado sempre durante a vigência do contrato. A necessidade de propor alterações que garantam a concessão do recesso remunerado dentro da vigência do contrato revela a visão atrasada e mesquinha das partes concedentes, contrariando o discurso da função social especialmente das organizações privadas com fins lucrativos, que valorizam sua marca quando dão publicidade ao fato de contribuírem com a formação de profissionais, oferecendo oportunidades de estágio. Tem-se, nesse diapasão, no nosso entendimento, uma legislação que já precariza as relações de trabalho e, mesmo assim, os capitalistas ou órgãos públicos que dela se beneficiam, encontram formas de burlá-la. 


\section{temporollis}

do estagiário, tal como previsto na legislação ao trabalhador celetista; proteção à gestante estagiária assegurando-a a vaga após 120 dias de afastamento; reserva de vagas para pessoas com deficiência, de maneira análoga ao que já está regulamentado em relação às oportunidades de empregos na iniciativa privada ${ }^{6}$ e nos concursos públicos; direito de livre associação7 da "classe de estagiários", de forma que por este meio, os estudantes possam negociar seus interesses junto às partes concedentes, controlar o cumprimento da legislação e atuar em parceria junto aos órgãos de fiscalização. Além disso, os legisladores vislumbram que tais associações poderiam desenvolver ações cívicas, trabalho voluntário e eventos culturais.

Já mencionamos, aqui, que só aparentemente essas proposições que procuram equiparar os direitos do estagiário aos direitos do empregado são benéficas àquele. Em face das tendências verificadas na realidade do mercado de trabalho no qual as vantagens econômicas para a contratação de trabalhadores estagiários por parte das empresas e órgãos públicos são incontestes, todas corroboram de modo disfarçado para os processos de precarização das condições de vida e de trabalho do conjunto dos trabalhadores. Na dinâmica própria do capital são geradas possibilidades objetivas para que a força de trabalho se reproduza com menor custo possível. No caso especialmente dos trabalhadores estudantes, o estágio é uma dessas possibilidades pelas quais os capitalistas podem socializar os custos pelo uso dessa força de trabalho e, o conjunto de direitos assegurados ou em vias de, "[...] não é mais que o conhecimento oficial do fato." (MARX, 1985, p. 86) Esse fato é assimilado pelo Estado que, por sua vez, tem o poder de dizer o direito por meio da norma. A "lei do estágio" diz: capital, eis um contingente de trabalhadores que terá de dispor da sua força de trabalho em condições ainda mais favoráveis para o processo de acumulação! Aproveite!

As proposições legislativas em comento acabam por colocar

\footnotetext{
6 Neste sentido remetemos o leitor ao disposto no art. 93 da Lei no 8.213/1991: Art. 93. A empresa com 100 (cem) ou mais empregados está obrigada a preencher de $2 \%$ (dois por cento) a $5 \%$ (cinco por cento) dos seus cargos com beneficiários reabilitados ou pessoas portadoras de deficiência, habilitadas, na seguinte proporção: I - até 200 empregados.....2\%; II - de 201 a 500.....3\%; III - de 501 a 1.000....4\%; IV - de 1.001 em diante. ......5\% (BRASIL, 1991).

7 Ora, tal proposição é mera demagogia, haja vista o fato de que o direito à liberdade de associação é garantido constitucionalmente, não havendo necessidade de nenhuma outra normativa neste sentido.
} 


\section{tempordis}

no horizonte da luta política da classe trabalhadora pautas que, no fim e ao cabo, terminam por legitimar o avanço da ofensiva do capital sobre o trabalho, prolongando, sobremaneira, a postura defensiva que o movimento dos trabalhadores tem assumido nas últimas décadas, em particular na realidade brasileira. Mais, elas acabam por dar azo à constituição de um segmento de trabalhadores de "segunda categoria" ou, ainda, podem servir de parâmetro para as contrarreformas trabalhistas, haja vista que, por trás dos aparentes avanços, estas proposições de garantias de direitos ao "exército de estagiários" logram importantes conquistas para o capital, na medida em que elas o desoneram. Se aceitas pelos trabalhadores estagiários, por que não podem o ser, também, pelos trabalhadores em geral?

Se situarmos este debate no processo de desenvolvimento da ordem do capital, tem-se a confirmação da tese defendida por Maria Cristina Soares Paniago (2003, p. 87) de que, quando se faz uma digressão histórica a respeito das lutas dos trabalhadores por direitos, "[...] a despeito das particularidades temporais e nacionais das conquistas sociais, [constata-se] uma linha de continuidade dos primórdios do capitalismo até nossos dias, uma vez que permanece intocada a regência do capital sobre o trabalho." No mesmo sentido, corroborando com esta análise, Mészáros (2004, p. 354) afirma que "[...] naturalmente, o Estado burguês só pode realizar a função 'protetora' em prol dos grupos de trabalho fragmentados e divididos até o ponto em que o exercício dessa função corresponda objetivamente aos interesses da classe dominante como um todo."

Além disso, esta forma precária de proteção dos estagiários contribui para o processo de fragmentação da luta política dos trabalhadores, pois mina a construção da identidade de classe e, se não inviabiliza, dificulta muito a vinculação daquele contingente de trabalhadores ao movimento sindical. Tal aspecto é essencial para que os processos de supressão, regressão e desregulamentação de direitos trabalhistas continuem avançando.

Esseconjunto dequestões, pela suaimportância, deveser objeto de discussões na pauta política do Serviço Social brasileiro, haja vista que elas confrontam princípios defendidos pela categoria, expressos em seu projeto ético-político. Não se trata mais de debatermos somente a problemática do estágio supervisionado em Serviço Social, mas de fazer as devidas mediações para compreendermos como as formas de implementação desse componente curricular 


\title{
temporollis
}

têm corroborado para a reiteração e intensificação dos processos de precarização do trabalho que afetam, significativamente, jovens estudantes. A política nacional de estágio preconizada pela legislação federal, no nosso entendimento, revela a imbricação entre capital, trabalho e Estado. E, neste sentido, são esclarecedoras as palavras de Mészáros (2015, p. 168-169):

\begin{abstract}
Devido à inseparabilidade das três dimensões do sistema do capital plenamente articulado - capital, trabalho e Estado -, é inconcebível emancipar o trabalho sem simultaneamente superar o capital e o Estado. Pois, paradoxalmente, o pilar material fundamental de suporte do capital não é o Estado, mas o trabalho em sua contínua dependência estrutural ao capital.
\end{abstract}

Por certo, a questão do estágio supervisionado, em particular, aqui, na área do Serviço Social, não pode ser pensada sem considerar as demandas do mercado de trabalho capitalista e as condições objetivas em que se materializam o exercício profissional. Contudo, aquelas demandas e constrangimentos do mercado também precisam passar pelo crivo da crítica, de modo a provocar tensões e evidenciar as contradições próprias da ordem que rege as relações laborais em comento. No caso específico do estágio, é preciso questionar até que ponto os processos de precarização do trabalho, ampliados por esta via, têm sido objeto de preocupação nos espaços de formação.

\section{Considerações Finais}

Nos termos aqui expostos, entendemos que os estágios profissionais estão constituindo, sim, formas precárias de trabalho em geral. Ainda que a legislação vigente contemple genericamente a relação entre estágio e área de formação no sentido de desenvolver as habilidades e competências previstas nos projetos de cursos, o que ocorre é que são priorizadas as demandas do mercado de trabalho. Essa lógica declina da dimensão pedagógica ao mesmo tempo em que valoriza os conhecimentos operacionais, práticos, instrumentais, aspectos amplamente analisados por vários estudos. $\mathrm{E}$, neste sentido, qualquer formação que tenha no seu horizonte $\mathrm{o}$ desenvolvimento da capacidade crítica dos estudantes é considera teoricista e desconectada do mundo real. Essa é uma realidade bastante conhecida pelo Serviço Social, considerando que o projeto 


\section{tempordis}

hegemônico da categoria se contrapõe a esta lógica mercantilista da educação e sofre ininterruptamente as pressões das demandas do mercado de trabalho.

Inúmeros estudos apontam como as organizações privadas e públicas têm usado os estagiários para substituir profissionais, haja vista ser uma mão de obra qualificada ou em processo de qualificação. As exigências que são feitas àqueles não diferem muito das que são feitas a estes, sendo certo que o direcionamento dado às práticas de estágio desconsidera o seu caráter educativo e reforça o caráter produtivista, substitutivo do emprego e até moralizante que atualmente tem sido defendido em muitas proposições legislativas em tramitação no parlamento brasileiro.

Em face da necessidade de muitos estudantes, especialmente de jovens oriundos das famílias trabalhadoras, se inserirem em alguma atividade remunerada, as vagas de estágio têm sido extremamente disputadas. Os processos seletivos, por isso, são muito rigorosos e semelhantes aos desenvolvidos quando da contratação de empregados. Em grandes empresas são contratados aqueles estudantes que possuem um nível avançado de inglês e espanhol, domínio de informática, experiência no exterior - intercâmbio - e que preferencialmente desenvolvem algum trabalho voluntário. Esses critérios, por si mesmos, eliminam a possibilidade de inserção de um enorme contingente de estudantes que são, cotidianamente, seduzidos ideologicamente pelas "benesses" do estágio. Nesse sentido, a condição de classe determina objetivamente a forma precária de inserção, especialmente dos jovens estudantes pobres, pela via do estágio, no mundo laboral.

No setor público o estágio tem, muitas vezes, servido para reiterar relações clientelistas e de favorecimentos políticos, contexto no qual os estudantes pobres, mas não exclusivamente, são pressionados a desempenhar suas atribuições com afinco, elevada qualidade e produtividade de maneira a serem "merecedores" da oportunidade oferecida.

$\mathrm{Na}$ área específica do Serviço Social, numa conjuntura marcada pela expansão do ensino superior, em particular pela modalidade de ensino a distância, os problemas para garantir a realização de um estágio profissional com qualidade se intensificaram. A falta de campos de estágio diante do número excessivo de estudantes que necessita 


\section{temporalis}

cumprir a obrigação curricular é uma realidade presente em todos os lugares do País. Neste particular, carecemos ainda de pesquisas que problematizem, por exemplo, séries históricas da oferta de vagas de estágio, de maneira que seja possível fazer algumas inferências sobre a elevação ou não das possibilidades de estágio não obrigatório em relação às oportunidades de estágio obrigatório, haja vista que este é uma responsabilidade precípua da formação.

Neste sentido, em face de tudo aqui exposto, colocamos e socializamos alguns questionamentos:

- Ao se posicionar na defesa de determinadas pautas de estudantes/trabalhadores estagiários que, contraditoriamente, encontram nos estágios uma forma de vender sua força de trabalho para garantir sua reprodução, não estaria a categoria contribuindo para a legitimação de processos de precarização do trabalho?

- Os estudantes/trabalhadores estagiários e docentes têm conseguido fazer a crítica a essa forma de contratação e uso da força de trabalho quando ela configura muito mais uma possibilidade de redução dos custos empresariais (ou públicos) do que uma oportunidade de os estudantes se aproximarem e apreenderem a realidade social na qual se processa o exercício profissional?

Estas e outras questões não significam, a priori, a negação da importância do estágio na formação do assistente social. Apenas, indicam inquietações políticas e teóricas que, esperamos, possam provocar novas reflexões e ações de enfrentamento aos processos de precarização do trabalho mediados pelo estágio profissional.

\section{REFERÊNCIAS}

ABEPSS. Associação Brasileira de Ensino e Pesquisa em Serviço Social. Política de estágio. Disponível em: <http://www.abepss.org. br/files/politica_nacional_estagio.pdf >. Acesso em 27 fev. 2014.

BRASIL. Constituição (1988). Constituição da República Federativa do Brasil: promulgada em 5 de outubro de 1988. 49. ed. São Paulo: Saraiva, 2014. 


\section{tempordis}

BRASIL. Lei n. 11.788, de 25 de setembro de 2008. Dispõe sobre o estágio de estudantes; altera a redação do art. 428 da Consolidação das Leis do Trabalho - CLT, aprovada pelo Decreto-Lei no 5.452, de 10 de maio de 1943, e a Lei no 9.394, de 20 de dezembro de 1996; revoga as Leis nos 6.494, de 7 de dezembro de 1977, e 8.859, de 23 de março de 1994, o parágrafo único do art. 82 da Lei no 9.394, de 20 de dezembro de 1996, e o art. 60 da Medida Provisória n. 2.16441, de 24 de agosto de 2001; e dá outras providências. Diário Oficial da União, Poder Executivo, Brasília-DF: 26 set. 2008. Disponível em: <http://www.planalto.gov.br/ccivil_03/_at02007-2010/2008/lei//11788. htm>. Acesso em: 30 jan. 2014.

. Lei n. 8.213, de 24 de julho de 1991. Dispõe sobre os planos de benefícios da previdência social e dá outras providências. Diário Oficial da União, Poder Executivo, Brasília-DF: 25 jul. 1991. Disponível em: <http://www.planalto.gov.br/ccivil_03/leis/L8213cons.htm>. Acesso em: 21 mar. 2016.

. Lei n. 8.662, de 7 de junho de 1993. Dispõe sobre a profissão de assistente social e dá outras providências. Diário Oficial da União, Poder Executivo, Brasília-DF: 8 jun. 1993. Disponível em: <http://www. planalto.gov.br/ccivil_03/leis/L8662.htm>. Acesso em: 27 fev.2014.

- Decreto-Lei n. 5.452, de 1 de maio de 1943. Aprova a consolidação das leis do trabalho. Diário Oficial da União, Poder Executivo, Rio de Janeiro-RJ: 9 ago. 1943. Disponível em: <http:// www.planalto.gov.br/ccivil_03/decreto-lei/del5452.htm>. Acesso em: 1 fev. 2014.

. Portaria PGR/MPU n. 567, de 13 de novembro de 2008. Regulamenta o programa de estágio no âmbito do Ministério Público da União e dá outras providências. Disponível em: <http://www2.prsc. mpf.mp.br/conteudo/servicos/concursos/arquivos/portaria-567-2008seus-anexos.pdf >. Acesso em: 5 mar. 2014.

CASTELO, Rodrigo. O novo desenvolvimentismo e a decadência ideológica do pensamento econômico brasileiro. Serviço Social \& Sociedade, São Paulo, n. 112, p. 613-636, out./dez. 2012. 


\section{temporollis}

CFESS. Conselho Federal de Serviço Social. Código de ética do/a assistente social. Aprovado em 13 de março de 1993, com as alterações introduzidas pelas resoluções CFESS n. 290/94, 293/94, 333/96 e 594/11. 10. ed. Brasília, DF: CFESS, 2012. Disponível em: <http://www. cfess.org.br/arquivos/CEP_CFESS-SITE.pdf>. Acesso em: 4 fev. 2014.

. Resolução n. 533, de 29 de setembro de 2008. Regulamenta a supervisão direta de estágio no serviço social. Disponível em: <http:// www.cfess.org.br/arquivos/Resolucao533.pdf>. Acesso em: $28 \mathrm{fev}$. 2014.

DELGADO, Maurício Godinho. Curso de direito do trabalho. 6. ed. São Paulo: Ltr, 2007.

. Curso de direito do trabalho. 7. ed. São Paulo: LTr, 2008.

IAMAMOTO, Marilda Villela. Renovação e conservadorismo no serviço social: ensaios críticos. São Paulo: Cortez, 1995.

LUKÁCS, György. Ontologia do ser social: os princípios ontológicos fundamentais de Marx. São Paulo: Livraria Editora Ciências Humanas, 1979.

LEHR, Roberto. Desafios para uma educação além do capital. In: JINKINGS, Ivana; NOBILE, Rodrigo (Orgs.). István Mészáros e os desafios do tempo histórico. São Paulo: Boitempo, 2011.

MARX, Karl. A miséria da filosofia. São Paulo: Global, 1985.

MTE. Ministério do Trabalho e Emprego. Nova cartilha esclarecedora sobre a lei do estágio. Brasília-DF: MTe, 2010. Disponível em: <http:// www.brasil.gov.br/economia-e-emprego/2016/08/cartilha-mteestagio.pdf>. Acesso em: 4 mar. 2014.

MÉSZÁROS, István. A montanha que devemos conquistar. São Paulo: 
Boitempo, 2015.

. O poder da ideologia. São Paulo: Boitempo, 2004.

PANIAGO, Maria Cristina Soares. As lutas defensivas do trabalho: contribuições problemáticas à emancipação. Serviço Social \& Sociedade, São Paulo, n. 76, p. 78-92, nov., 2003.

POCHMANN, Márcio. A batalha pelo primeiro emprego: a situação atual e as perspectivas do jovem no mercado de trabalho brasileiro. 2. ed. São Paulo: Publisher Brasil, 2007.

PALMEIRA SOBRINHO, Zéu. O contrato de estágio e as inovações da Lei 11.788/2008. Revista LTr: legislação do trabalho, São Paulo, v.72, n.10, p.1173-1188, out., 2008. 


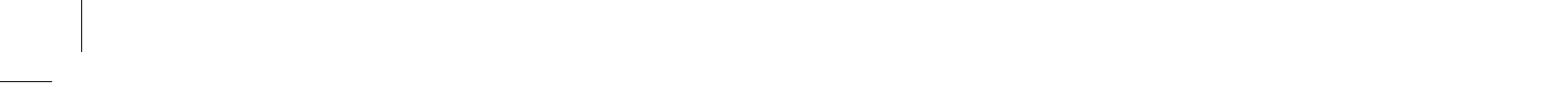

